\title{
Thyroid and adrenal relationships
}

\author{
Victor PARSONS \\ D.M., M.R.C.P. \\ Senior Lecturer in Medicine \\ IAN RAMSAY \\ M.D., M.R.C.P., M.R.C.P.E. \\ Lecturer in Medicine \\ Department of Medicine, King's College Hospital Medical School, \\ Denmark Hill, London, S.E.5
}

\section{Summary}

A brief review of the actions of adrenal medullary and thyroid hormones is presented and the ways in which they interact are examined. It is concluded that thyroid hormone produces the necessary intracellular environment without which the steady state and emergency actions of cathecholamines would be vitiated. In hyperthyroidism the increased concentration of thyroid hormones results in a lowering of the threshold for catecholamine action. For this reason it is possible to alleviate many of the symptoms of thyrotoxicosis by means of drugs which block $\beta$-adrenergic receptors.

Attention is also drawn to the simultaneous occurrence of thyroid and adrenal disease, in the hope that this will encourage the search for further links in this field of endocrinology.

\section{Introduction}

The relationship between the thyroid and the adrenal glands has interested surgeons, physicians and pharmacologists for many years. The subject can be examined under two broad headings; first, the relationship between the hormones of the adrenal medulla and the thyroid, and secondly, the coincidence of separate thyroid and adrenal disease.

\section{Adrenal medullary and thyroid relationships}

Patients with phaeochromocytoma often present with symptoms which are almost identical to those of hyperthyroidism, namely weight loss, heat intolerance, sweating, palpitations, anxiety and tremor (Gifford et al., 1964). Hyperthyroid patients, on the other hand, may sometimes show acute psychiatric features which mimic the toxic catecholamine effects of monoamine oxidase inhibiting drugs (Dewhurst, 1965). These similarities have led to the formation of many hypotheses about the relationship between the adrenal medullary and thyroid hormones. The difficulty in reconciling and in amalgamating the different theories lies in the probable variability of this relationship in various disease states such as hypo- and hyperthyroidism.

Over the last 10 years more light has been shed on this problem and the aim of this review is to concentrate on the cellular mechanisms which seem to provide a more logical explanation for the interaction of the hormones from the two different glands (Ellis, 1956; Harrison, 1964 ; Waldstein, 1966 ; Svedmyr, 1966). Following on from this hypothesis come the therapeutic opportunities offered by the adrenergic blocking drugs which have been proved so useful in the early management of thyrotoxicosis.

\section{The mode of action of catecholamines}

Catecholamines have a variety of effects. They act as neurotransmitters in adrenergic nerves, have direct effects upon cardiac contraction and produce metabolic changes in fat, liver and muscle cells (Fig. 1).

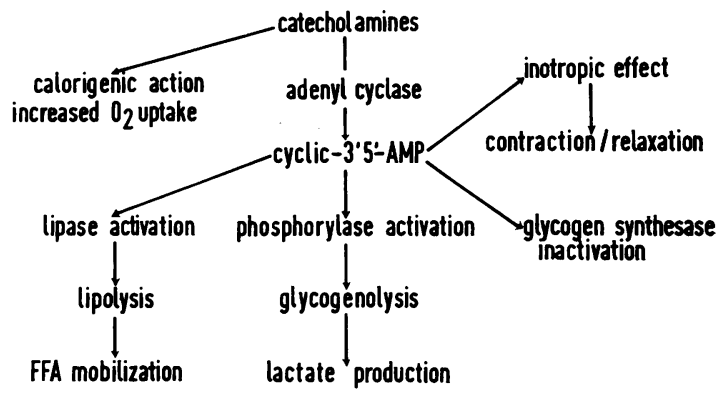

FIG. 1. Some consequences of catecholamine action.

In 1948 Ahlquist proposed that the difference in the action of catecholamines on various tissues could be explained by the presence of two separate types of receptor, $\alpha$ and $\beta$ (Ahlquist, 1967 ; Furchgott, 1967). $\alpha$-Receptors, which respond in diminishing order to adrenaline, noradrenaline, phenylephine and isoproterenol and produce effects such as arteriolar constriction, can be blocked by ergot and phentolamine. $\beta$-Receptors, 
on the other hand, respond primarily to isoproterenol, followed by adrenaline, noradrenaline and phenylephrine. Ergot and phentotolamine have little, if any, effect upon $\beta$-receptor responses (e.g. bronchial muscle relaxation), but these can be blocked by a different series of agents such as pronethalol, propranolol and dichloroisoproterenol. Ahlquist's rather tidy original concept has unfortunately had to be modified by the finding of both types of receptor is smooth muscle and it is possible that there is more than one kind of $\beta$-receptor (Furchgott, 1967).

In recent years the importance of adenosine$3^{\prime}, 5^{\prime}$-phosphate (cyclic-3',5'-AMP) as an intracellular trigger mechanism activated by catecholamines has been emphasized (Sutherland \& Robison, 1966). The concentration of this potent substance depends on the activity of adenyl cyclase for its formation and of phosphodiesterase for its inactivation. Thyroid hormone increases the formation of adenyl cyclase and catecholamines have an activating effect on the enzyme so that either of them, or both, can cause an increase in the amount of cyclic-3',5'-AMP (Brodie et al., 1966). A sudden increase in activity of adenyl cyclase triggers off a metabolic cascade (Fig. 2) which, by activating liver and muscle phosphorylase, causes the production of glucose-1-phosphate from glycogen (Bowness, 1966) and by activating adipose tissue lipase results in the breakdown of triglycerides to free fatty acid (FFA) and glycerol (Rizack, 1964 ; Brodie et al., 1966).

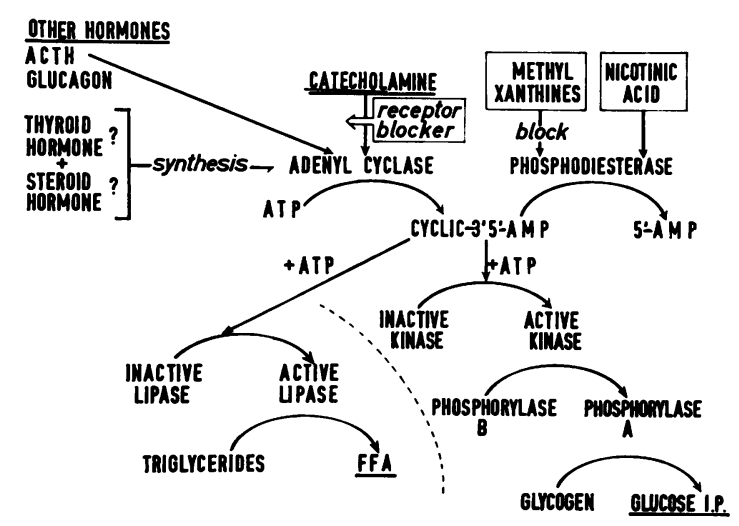

Fig. 2. The actions of catecholamines, other hormones and various drugs on carbohydrate and fat metabolism.

It is now known that triglycerides as well as glycogen are stored in skeletal (Brodie et al., 1966) and cardiac muscle and that they are subject to the same regulatory mechanisms as in adipose tissue. It has been shown that the release of free fatty acids from myocardial triglyceride occurs quite independently of the mechanical activity of the heart (Challoner \& Steinberg, 1965). Thus, in addition to the regulation of carbohydrate and lipid metabolism by insulin and other hormones, there appears to be an adrenergic control which can be rapidly called into play during periods of increased demand. As a consequence of the fluxes of glucose and FFA which it produces, insulin secretion is reduced and further glycogen and triglyceride storage is prevented (Himms-Hagen, 1967).

Studies of the effects of adrenaline on the perfused rat heart have shown a rise in cyclic$3^{\prime}, 5^{\prime}$-AMP at the start of inotropic contraction, before the concentration of phosphorylase $A$ and of other breakdown products of glycogenolytic metabolism rises (Williamson, 1966).

The actions of $\beta$-adrenergic blocking agents on the metabolic effects of catecholamines have not only helped to clarify the role of adrenergic mechanisms, but have also proved useful in certain clinical situations characterized by catecholamine overactivity. These $\beta$-blocking drugs decrease cardiac contractile force, cardiac phosphorylase activation, muscle and liver glycogeno lysis and adipose tissue lipolysis, though it iso possible that not all the effects are mediated? through the adrenergic receptors (Mayer, Williams \& Smith, 1967). The $\beta$-blockers give additional evidence that the inotropic effect of catecholamines on the heart is mediated via cyclic$3^{\prime}, 5^{\prime}$-AMP. Pronethalol, in a concentration which by itself produced no metabolic changes in the heart, prevented both the cyclic-3',5'-AMP rise and the inotropic response when adrenaline was added (Sutherland \& Robison, 1966). The effect upon the inotropic response may be mediated by alterations in the movement of calcium ions (Koch-Weser \& Blinks, 1963), or by a local anaesthetic property of $\beta$-blockers which reduces the explosive increase of sodium conductance across the cell membrane at the time of depolarization (Morales-Aguilera \& Vaughan Williams, 1965).

The mode of action of thyroid hormones

'Investigating the mechanism of action of the thyroid hormones is like peeling an onion. Not only may it bring tears to the eyes, but, after such successful step, one is left with the layer beneath' (Wolff \& Wolff, 1964).

The thyrotoxic state demonstrates admirably the protean actions of the thyroid hormones, for no tissue is spared and the symptoms emanate 
from every organ in the body. Thus, there is weight loss and heat intolerance, palpitations and breathlessness, muscular weakness, anxiety and looseness of the bowels. Investigations show a raised basal metabolic rate, decreased glucose tolerance and raised plasma FFA, decreased cholesterol but raised phosphate levels and an increase in the urinary excretion of hydroxyproline, indicating that there is hardly a single metabolic process which is not affected by excess thyroid hormone.

Thyroid hormone may act on several of the cell's control mechanisms and these vary from tissue to tissue. The supply of substrate may be changed by alterations in membrane permeability and intracellular transport mechanisms. The substrate is then subject to any modifications in the concentration of enzymes, their inhibitors and facilitators, working in the presence of nucleotides, cofactors and ions; the cellular processes may also be affected by the removal of the products of metabolism by oxidative phosphorylation (Racker, 1965).

By examining substrate and enzyme concentrations under steady conditions some idea can be gained as to the critical 'throttle steps' in cellular metabolism, and it is these points which have attracted particular attention in the search for the mode of action of thyroid hormones. The control systems are so interconnected that it is difficult to determine any primary site of action. Interest has ranged from a study of transport changes, uncoupling of oxidative phosphorylation, chelation of ions and synthesis of enzyme proteins (Tapley, 1964).

Hoch $(1962$, 1968) postulated that, because the oxidation of so many substrates is stimulated in thyrotoxicosis, the final common pathway for the action of thyroid hormones must lie within the mitochondria. It is in the mitochondria that three adenosine triphosphate (ATP) molecules are formed for each atom of oxygen utilized, giving a phosphate: oxygen $(\mathrm{P}: \mathrm{O})$ ratio of 3 . When this occurs the system is said to be "tightly coupled'. If less ATP is produced for each atom of oxygen consumed, the system is regarded, according to degree, as 'loosely coupled' or 'uncoupled'. Thyroxine in various concentrations has been shown to produce both loose coupling and uncoupling. The sites of action are mainly at the adenosine diphosphate (ADP), ATP and $P_{i}-$ ATP exchange points and also at the first phosphorylation site (flavoprotein-diphosphopyridine nucleotide), which has been shown to be very sensitive to inhibition by thyroxine (Chance \& Hollunger, 1963). The possibility that an effect on oxidative phosphorylation is important in thyrotoxicosis has been demonstrated by the finding of loose coupling in the muscle mitochondria of these patients (Hoch, 1962). Moreover, the muscles which display the greatest degree of wasting and weakness in thyrotoxicosis are those which contain the greatest number of mitochondria (Hoch, 1962 ; Ramsay, 1966). The uncoupling theory is attractive, but thyroid hormone may have some other important actions. For instance there may be an alteration in enzyme activity, such as the increase in adenyl cyclase in adipose tissue (Brodie et al., 1966), and structural changes which produce swelling in the mitochondria. On the other hand, Tata and his colleagues (1963) have shown that the thyroxine-induced incorporation of amino acids can take place even in tissues where no depression of the $\mathbf{P}: \mathbf{O}$ ratio can be demonstrated.

These rapid and toxic effects on the mitochondria are produced by very high levels of thyroid hormone. Slower changes also take place through the control of the rate of synthesis of specific cellular constituents. Tata (1964), working on the cellular changes induced by the introduction of thyroid hormones in thyroidectomized rats and the induction of metamorphosis in amphibia, has shown the sequential stimulation of ribonucleic acid (RNA) and protein synthesis in various key tissues. The first change noted was an increase in the synthesis of nuclear RNA, followed by magnesium-activated RNA polymerase, leading to an accumulation of newly formed ribosomes and polysomes which turn out freshly labelled protein from labelled amino acids. These changes were also associated with the aggregation and synthesis of the phospholipid matrix of newly formed ribosomes (Tata, 1967). Thus thyroid hormones seem to act in a similar fashion to growth hormone and testosterone, in that there is an increased proliferation of microsomal membranes at the same time as hormone-induced increases in cytoplasmic RNA and protein synthetic activity in vivo. A summary of the possible sites of thyroid hormone action is shown in Fig. 3.

As has been mentioned already, it is difficult to disentangle the normal actions of the thyroid hormones from those that occur during thyrotoxicosis. In the latter situation, toxic effects may override normal control function; for example, the transport of glucose into cells is increased (Danoff \& Laster, 1962), intestinal mobility is affected (Johansson, 1966), sodium transport is heightened (Green \& Matty, 1963), the renal handling of water and phosphate is altered (Parsons \& Anderson, 1964) and there is a change in the cellular response to, and fixation of, di- 
goxin (Doherty \& Perkins, 1966). Whether these and many other metabolic changes are linked to altered protein synthesis, to mitochondrial swelling or to uncoupled oxidation, it is impossible to say on present evidence.

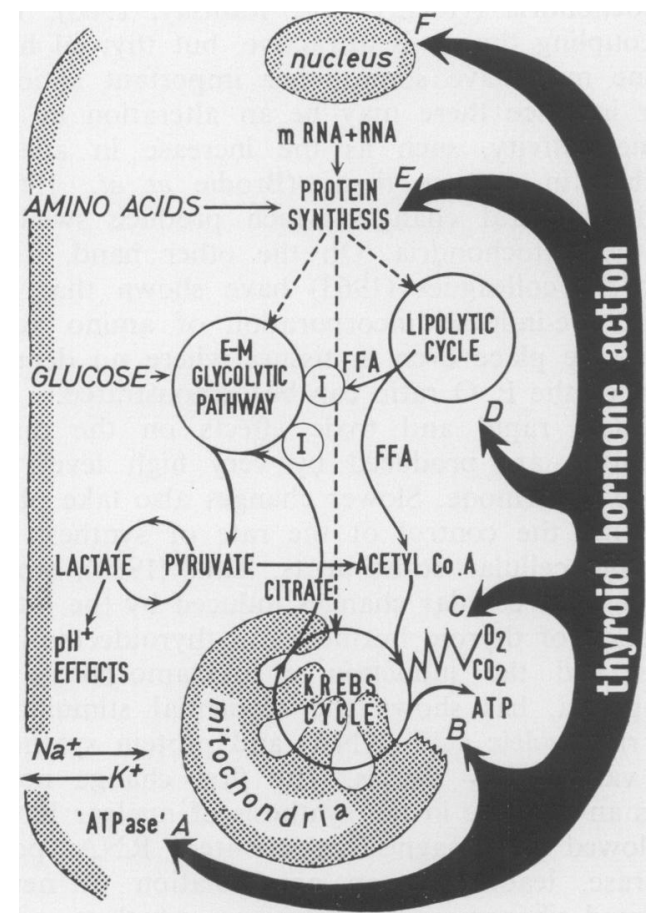

FIG. 3. Composite hypothesis for the possible sites of action of thyroid hormones. (A) Ion transport via ATPase alteration. (B) Mitochondrial permeability actions. (C) Uncoupling of oxidative phosphorylation. (D) Enhancement of lipolytic enzymes. (E) and (F) Alterations in protein synthesis via changes in RNA and ribosomal structural synthesis. (I) Inhibitory sites of action of citrate and FFA on the Embden-Meyerhof pathway.

Catecholamine and thyroid hormone interactions in hyper- and hypothyroidism

Alterations in catecholamine release and production. Investigations into the possibility of an increase in the production and release of catecholamines in the hyperthyroid state have been carried out, but have been generally negative (Wiswell et al., 1963 ; Harrison et al., 1967).

Reflex stimuli, such as hypoglycaemia and abrupt postural changes, which normally release adrenaline and noradrenaline respectively, have not been shown to increase the output of these hormones in either hyper- or hypothyroidism (Harrison, 1961) and it has been suggested that in both situations the adrenal medulla may be under-reactive (Leak et al., 1963). Estimations of catecholamines in the plasma have not revealed abnormal amounts in uncontrolled hyperthyroidism, but increased concentrations may be recorded in the same patients during the severe stress of a thyrotoxic crisis (Maddock, Pedersen \& Coller, 1937).

Alterations in catecholamine destruction. The possibility must be raised that the observed potentiation of the calorigenic effects of infused catecholamines could be due to a decrease in their inactivation by monoamine oxidase (MOA) or by catechol-ortho-methyl transferase (COMT). However, a study of the disposal of infused catecholamines in euthyroid and triiodothyroninetreated individuals revealed no difference between the two groups; and a study of ${ }^{3} \mathrm{H}$-labelled adrenaline and metadrenaline in the tissues of normal and thyroxine-treated rats showed similar concentrations in both (Svedmyr, 1966). It therefore appears that the potentiation of certain effects of catecholamines after the administration of thyroid hormones must be due to changes in the receptor cell, rather than to reduced uptake or breakdown of catecholamines locally.

Possible intracellular potentiating mechanisms Rats whose adrenergic responses have beeno blocked behave in a similar fashion to adrenalectomized animals when faced with external stimurif which demand an increased expenditure of energy (Brodie et al., 1966). Their metabolism under basal conditions is virtually normal, but if exposed to cold or muscular work neither of the two groups of rats can bring about piloerection, vasoconstriction or shivering, nor can they produce the normal lipolytic or glycogenolytic responses to adrenaline (Bray \& Goodman, 1965; Bray, 1966). All these changes are partly restored by the administration of aldosterone as well as glucocorticoids and it is, therefore, thought that normal ionic concentrations in sympathetic receptors are important for proper function.

The experimental situation in these rats is very similar to that of patients in myxoedema coma who are unable to conserve or generate heat. Studies show that adipose tissue from hypothyroid rats has a poor lipolytic response to the action of adrenaline, while the converse is true of tissue from hyperthyroid animals (Debons \& Schwartz, 1961 ; Felt et al., 1962). Because thyroid hormones increase the amount of adenyl cyclase in adipose tissue (Brodie et al., 1966), a normal quantity of circulating catecholamines is capable of enhancing the production of cyclic3',5'-AMP. Likewise it has been shown (Hornbrook, Quinn \& Siegel, 1965) that thyroid ad- 
ministration potentiates the catecholamines' effect on myocardial glycogenolysis, though it does not seem to produce any changes in haemodynamic responses (Aoki et al., 1965).

A summary of possible relationships is shown in Fig. 4.

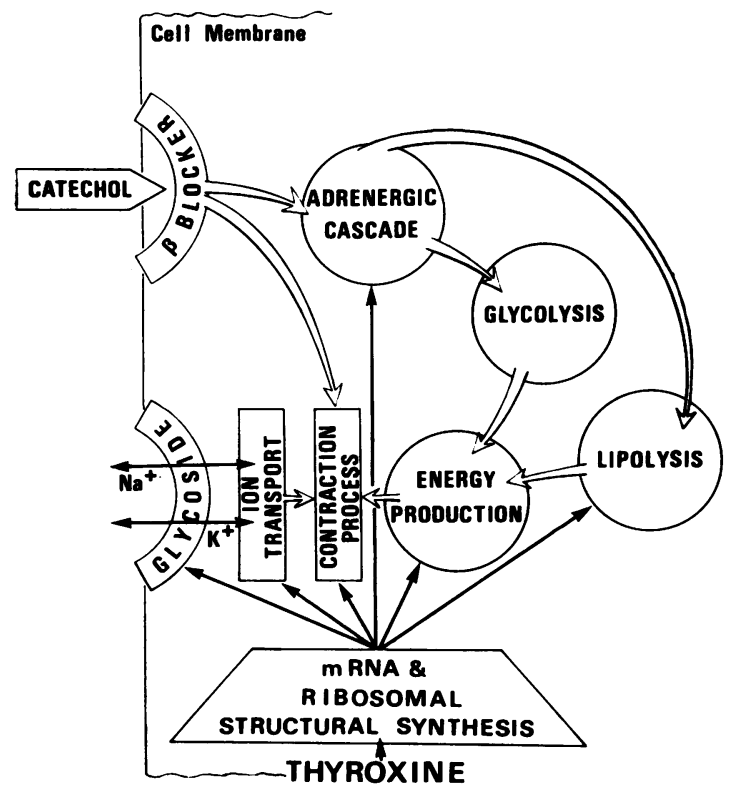

FIG. 4. The triggering action of catecholamines on thyroxine-prepared cycles. $\mathrm{mRNA}=$ Messenger ribonucleic acid.

\section{Therapeutic applications}

Most of the evidence points to an enhancing effect by thyroid hormone in thyrotoxicosis on normal amounts of circulating catecholamines. Certainly many of the symptoms of the disease are explicable on this basis and this has lead to the use of adrenergic blockade in treatment.

Knight (1945) observed the effects of sympathetic blockade, obtained by spinal anaesthesia, on thyrotoxic crisis. He noted prompt and dramatic relief of the tachycardia, high oxygen consumption and the hyperthermia. Later others have tried various sympatholytic drugs in the treatment of thyrotoxicosis. Guanethidine, which depletes noradrenaline stores in peripheral adrenergic nerve endings, has been shown to reduce the tachycardia without altering the serum protein-bound iodine concentration (Gaffney, Braunwald \& Kahler, 1961 ; De Groot et al., 1961 ; Lee, Bronsky \& Waldstein, 1962 ; Leak, 1963) and to diminish the eye signs of lid-lag and retraction (Sneddon \& Turner, 1966). One of its disadvantages is postural hypotension, which is especially liable to occur in a thyrotoxic patient with dilated peripheral blood vessels (Leak, 1963). Reserpine has also been used (Canary et al., 1957; Wayne, 1960). It depletes both central and peripheral nervous tissue of catecholamines, but it tends to produce depression and several features of the carcinoid syndrome have been reported following its use in high dosage (Blumenthal, Davis \& Doe, 1965).

More recently attention has been drawn to blockade of the $\beta$-adrenergic receptors with pronethalol (now withdrawn) and propranalol. Many of the symptoms of thyrotoxicosis can be ameliorated by this means. Tachycardia diminishes and occasionally arrhythmias are abolished (Turner, Granville-Grossman \& Smart, 1965 ; Robillard, Klotz \& Perrault, 1967), tremor is reduced (Marsden et al., 1968) and features of anxiety and even psychosis may be eliminated (Parsons \& Jewitt, 1967). Some workers, on the other hand, have been unable to show that propranalol had any significant effect on haemodynamic responses to isoprenaline and amyl nitrate administration in experimental hyperthyroidism (Wilson et al., 1966). One can never be certain, however, that the experimental conditions match those exactly of the disease. The major disadvantages of the use of propranalol are its tendency to cause cardiac failure in those with diseased hearts and broncho-constriction in patients with asthma or chronic bronchitis. However, if proper care is taken, propranalol is of great value in the treatment of severe thyrotoxicosis and crisis, and for the relief of symptoms until anti-thyroid drugs begin to have a therapeutic effect.

The association of thyroid with adrenal disease

Primary adrenal disease has been associated in three different ways with thyroid disorders. They are:

1. Thyroid and adrenal insufficiency (Schmidt's syndrome).

2. Hyperthyroidism and adrenal insufficiency.

3. Medullary carcinoma of the thyroid and phaeochromocytoma.

Thyroid and adrenal insufficiency (Schmidt's syndrome)

Schmidt (1926) was the first to describe two patients with Addison's disease and lymphocytic infiltration of the thyroid. Carpenter and his colleagues have recently (1964) reviewed the literature on associated thyroid and adrenal failure and added a further fifteen cases of their own. The connection can probably best be explained on an autoimmune basis. It is now generally 
accepted that the thyroid antibodies in thyroiditis are autoantibodies (Roitt \& Doniach, 1960). Recently two groups of workers (Blizzard, Chee \& Davis, 1967; Irvine, Stewart \& Scarth, 1967) have demonstrated that a majority of female patients with idiopathic Addison's disease have antibodies to adrenal tissue; the association was not nearly so strong in male patients. Thyroid antibodies were also found in over half Irvine et al.'s (1967) Addisonian patients, and in a fifth of those of Blizzard et al. (1967). Thus there is now some laboratory basis for the previously noted clinical association, but it should be noted that although serological evidence of thyroidities is common in patients with adrenalitis the converse is much rarer (Blizzard et al., 1967 ; Irvine et al., 1967).

\section{Hyperthyroidism and adrenal insufficiency}

Burke \& Feldman (1965) reviewed twenty-six previously reported cases of hyperthyrodism associated with Addison's disease and added a further case of their own, in which they demonstrated the presence of anti-adrenal and antithyroid antibodies. Frederickson (1951) discovered that the incidence of hyperthyroidism in patients with Addison's disease was 4.4\% which is about ten times higher than would be expected in the general population.

Once again it seems likely that ultimately the connection will be found to lie in the all-embracing term of 'autoimmune disease', for it is now thought (Lancet, 1967) that long-acting thyroid stimulator, which is a $\gamma$-globulin, is probably the cause of thyrotoxicosis and that it behaves as an antibody (Kabir et al., 1966) It is interesting to note in this context that two of the patients in a recent survey of thyroid and adrenal failure originally had hyperthyroidism (Carpenter et al., 1964).

\section{Medullary carcinoma of the thyroid and phaeo- chromocytoma}

The association of carcinoma of the thyroid and phaeochromocytoma has recently been reviewed by Williams $(1965,1967)$ and Urbanski (1967). Williams (1967) found that out of the thirty-five cases published, twenty-six had a carcinoma of the medullary type. This is normally a rare tumour, forming only $6.5 \%$ of all thyroid carcinomas (Woolner et al., 1961). Histologically it is solid, not follicular, and is characterized by islands of regular cells with an abundant granular cytoplasm and varying amounts of amyloid in the stroma (Williams, 1967). There is a high incidence of lymph-node metastases (Williams, 1965).
Urbanski (1967) noted that of the twenty-nine cases of thyroid carcinoma and phaeochromocytoma he reviewed, the carcinoma was of the medullary type in twenty. There was a family history of thyroid carcinoma in eight and of familial phaeochromocytoma in eleven. Although only $11 \%$ of sporadic phaeochromocytomas are bilateral (Graham, 1951), the tumours are multiple in $46 \%$ of familial cases (Nourok, 1964) and when associated with thyroid carcinoma as many as $76 \%$ are bilateral.

The association between phaeochromocytoma and von Recklinghausen's disease is well known (Glushien, Mansuy \& Litman, 1953) and Williams (1965) explains this on the basis of the neuroectodermal origins of both disorders. He thinks that there is little evidence that medullary carcinoma arises from thyroid epithelial cells and postulates that its origin, too, may be neuroectodermal. The evidence for this is strengthened by his report of two cases of multiple mucosal neuromas in association with medullary thyroid carcinoma and phaeochromocytoma (Williams \& Pollock, 1966). Urbanski (1967) noted that both thyroid medullary carcinoma and phaeochromocytoma appeared to be inherited as an autosomal dominant.

Williams (1965) warned against confusing the association of thyroid medullary carcinoma and phaeochromocytoma with the better-known mul tiple endocrine adenoma syndrome; the two appeared to be quite distinct.

\section{Acknowledgments}

We are grateful to Professor J. Anderson for his encouragement and to the National Lending Library for Science and Technology, Boston Spa, Yorkshire, for a Medlars search.

\section{References}

AHLQUist, R.P. (1967) Development of the concept of alpha and beta adrenotrophic receptors. Ann. N.Y. Acad. Sci. 139, 549.

AOKI, V.S., WILSON, W.R., TheIlen, E.O., LUKENSMEYeR, W.W. \& LeAVERTON, P.E. (1965) Effects of triiodothyronine on the haemodynamic response to epinephrine in normal subjects. Clin. Res. 13, 398.

Blizzard, R.M., Chee, D. \& Davis, W. (1967) The incidence of adrenal and other antibodies in the sera of patients with idiopathic adrenal insufficiency (Addison's Disease). Clin. exp. Immunol. 2, 19.

Blumenthal, M., Davis, R. \& Doe, R.P. (1965) Carcinoid syndrome following reserpine therapy in thyrotoxicosis. Arch. intern. Med. 116, 819.

BowNEss, J.M. (1966) Epinephrine: cascade reactions and glycogenolytic effect. Science, 152, 1370.

BrAY, G.A. (1966) Studies on the sensitivity to catecholamines after thyroidectomy. Endocrinology, 79, 554.

BraY, G.A. \& Goodman, H.M. (1965) Studies on the early effects of thyroid hormones. Endocrinology, 76, 323.

Brodie, B.B., Davies, J.I., Hynie, S., Krishna, G. \& Weiss, B. (1966) Interrelationships of catecholamines with other endocrine systems. Pharmacol. Rev. 18, 273. 
Canary, J.J., SchaAf, M., Duffy, B.J. \& Kyle, L.H. (1957) Effects of oral and intramuscular administration of reserpine in thyrotoxicosis. New Engl. J. Med. 257, 435.

Carpenter, C.C.J., Soloman, N., Silverberg, S.G., Bledsoe, T., NoRThCutt, R.C., Klinenburg, J.R., BenNetT, I.L., JR \& HARVeY, A.McG. (1964) Schmidt's syndrome (thyroid and adrenal insufficiency): a review of the literature and a report of fifteen new cases including ten instances of co-existent diabetes mellitus. Medicine (Baltimore), 43, 153.

Challoner, D.R. \& Steinberg, D. (1965) Metabolic effect of epinephrine on the $\mathrm{QO}_{2}$ of the arrested, isolated, perfused rat heart. Nature (Lond.), 205, 602.

Chance, B. \& Hollunger, G. (1963) Inhibition of electron and energy transfer in mitochrondria. IV. Inhibition of energy linked diphosphopyridine mucleotide reduction by uncoupling agents. $J$. biol. Chem. 238, 445.

DANOFF, D. \& LASTER, L. (1962) In vitro endocrine stimulation of active transport in the small intestine of hamster. J. clin. Invest. 41, 1376.

Debons, A.F. \& Schwartz, I.L. (1961) Dependence of the lipolytic action of epinephrine in vitro upon thyroid hormone. J. Lipid Res. 2, 86.

De Groot, W.J., Leonard, J.J., Paley, H.W., Johnson, J.E. \& WARREN, J.V. (1961) The importance of autonomic integrity in maintaining the hyperkinetic circulatory dynamics of human hyperthyroidism. J. clin. Invest. 40, 1033.

DEWHURST, W.G. (1965) On the chemical basis of mood. J. psychosom. Res. 9, 115.

DoherTy, J.E. \& Perkins, W.H. (1966) Digoxin metabolism in hypo and hyperthyroidism. Studies with tritiated digoxin in thyroid disease. Ann. intern. Med. 64, 489.

ELlis, S. (1956) The metabolic effects of epinephrine and related amines. Pharmacol. Rev. 8, 485.

Felt, V., Schovanec, B., Benes, P., Plzak, F. \& Vrbensky, V. (1962) The effect of thyroid state, adrenaline and glucose in the release of free fatty acids from adipose tissue. Experientia, 18, 379.

FreDERICKSON, D.S. (1951) Effect of massive cortisone therapy on thyroid function. J. clin. Endocr. 11, 760.

FURCHGOTT, R.F. (1967) The pharmacological differentiation of adrenergic receptors. Ann. N.Y. Acad. Sci. 139, 553.

Gaffney, T.E., Braunwald, E. \& KaHLER, R.L. (1961) Effects of guanethidine on triiodothyronine-induced hyperthyroidism in man. New Engl. J. Med. 265, 16.

Gifford, R.W., KVAle, W.F., Maher, F.T., Roth, G.M. \& Priestley, J.J. (1964) Clinical features, diagnosis and treatment of pheochromocytoma: a review of 76 cases. Proc. Mayo Clin. 39, 281.

Glushien, A.S., Mansuy, M.M. \& Litman, D.S. (1953) Pheochromocytoma. Its relationship to the neurocutaneous syndromes. Amer. J. Med. 14, 318.

GraHAM, J.B. (1951) Collective review: pheochromocytoma and hypertension. An analysis of 207 cases. Int. Abstr. Surg. 92, 105.

Green, K. \& Matty, A.J. (1963) Action of thyroxine on active sodium transport in isolated membranes of Bufo bufo. Gen. comp. Endocr. 3, 244.

HARRISON, T.S. (1961) Reflex liberation of catechol hormones in hyperthyroidism. J. surg. Res. 1, 77.

HARrison, T.S. (1964) Adrenal medullary and thyroid relationships. Physiol. Rev. 44, 161.

Harrison, T.S., Siegel, J.H., Wilson, W.S. \& Weber, W.J. (1967) Adrenergic reactivity in hyperthyroidism. Arch. Surg. 94, 396.

Himms-HAGEN, J. (1967) Sympathetic regulation of metabolism. Pharmacol. Rev. 19, 367.

Hoch, F.L. (1962) Thyrotoxicosis as a disease of mitochondria. New Engl. J. Med. 266, 446, 498.
HoCH, F.L. (1968) Biochemistry of hyperthyroidism and hypothyroidism. Postgrad. med. J. 44, 347.

HoRnbrooK, K.R., QUINN, P.V. \& Siegel, J.H. (1965). Thyroid hormone regulation of cardiac glycogen metabolism. Biochem. Pharmacol. 14, 925.

Irvine, W.J., Stewart, A.G. \& SCarth, L. (1967) A clinical and immunological study of adrenocortical insufficiency (Addison's disease). Clin. exp. Immunol. 2, 31.

JoHANSSON, H. (1966) Gastrointestinal motility functions related to thyroid activity. Acta chir. scand. Suppl. 359, 1.

Kabir, D.J. el, Benhamou-GlynN, N., DoniaCh, D. \& RoITT, I.M. (1966) Absorbtion of thyroid-stimulating globulin from thyrotoxic sera by organ homogenates. Nature (Lond.), 210, 319.

KNIGHT, R.T. (1945) The use of spinal anaesthesia to control sympathetic overactivity in hyperthyroidism. Anaesthesioology, 6, 225.

KOCH-WeSER, J. \& BLINKS, J.R. (1963) The influence of the interval between beats on myocardial contractility. Pharmacol. Rev. 15, 601 .

LANCET (1967) Leading article: Thyrotoxicosis. Lancet, ii, 1186.

LEAK, D. (1963) Adrenergic blockade and thyrotoxicosis. Acta Endocr. (Kbh.), 43, 131.

Leak, D. Brunjes, S., Johns, V.J. \& StarR, P. (1963) Excess thyroid medication and adrenal medullary response to insulin hypoglycaemia. J. clin. Endocr. 23, 834.

Lee, W.Y., Bronsky, W. \& Waldstein, S.S. (1962) Studies of thyroid and sympathetic nervous system interrelationships. II. Effects of guanethidine on manifestations of hyperthyroidism. J. clin. Endocr. 22, 879.

Maddock, W.G., Pedersen, S. \& Coller, F.A. (1937) Studies of the blood chemistry in thyroid crisis. J. Amer. med. Ass. 109, 2130.

Marsden, C.D., Gimlette, T.D.M., McCallister, R.G., OWEN, D.A.L. \& MiLleR, T.N. (1968) Effects of betaadrenergic blockade on finger tremor and Achilles reflex time in anxious and thyrotoxic patients. Acta endrocr. (Kbh.), 57, 353.

MAYER, S.E., Williams, B.J. \& SMith, J.M. (1967) Adrenergic mechanisms in cardiac glycogen metabolism. Ann. N.Y. Acad. Sci. 139, 686.

Morales-Aguilera, A. \& Vaughan Williams, E.M. (1965) The effect on cardiac muscle of beta-receptor antagonists in relation to their activity as local anaesthetics. Brit. $J$. Pharmacol. 24, 332.

Nourok, D.S. (1964) Familial pheochromocytoma and thyroid carcinoma. Ann. intern. Med. 60, 1028.

Parsons, V. \& ANDERson, J. (1964) The maximal tubular resorptive rate for inorganic phosphate in thyrotoxicosis. Clin. Sci. 27, 314.

Parsons, V. \& JeWITT, D.E. (1967) The use of beta adrenergic blockade in thyrotoxic crisis, arrhythmia and tachycardia. Postgrad. med. J. 43, 756.

RACKER, E. (1965) Mechanisms in Bioenergetics. Academic Press, New York.

RAMSAY, I.D. (1966) Muscle dysfunction in hyperthyroidism. Lancet, ii, 931.

RizACK, M.A. (1964) Activation of an epinephrine sensitive lipolytic activity from adipose tissue by adenosine $3^{\prime} 5^{\prime}$ phosphate. J. biol. Chem. 239, 392.

Robillard, M., Klotz, B. \& Perrault, M. (1967) L'inhibition des récepteurs beta-adrenergiques dans la traitement de la maladie de Basedow. Presse méd. 75, 897.

RoITT, I.M. \& DoniACH, D. (1960) Thyroid auto-immunity. Brit. med. Bull. 16, 152.

SchмidT, M.B. (1926) Eine biglandulăre Erkrankung (Nebennieren und Schilddrüse) bei morbus Addisonii. Verh. dtsch. path. Ges. 21, 212.

Sneddon, J. M. \& TURner, P. (1966) Adrenergic blockade and the eye signs of thyrotoxicosis. Lancet, ii, 525. 
Sutherland, E.W. \& Robison, G.A. (1966) The role of cyclic-3'5'-A.M.P. in responses to catecholamines and other hormones. Pharmacol. Rev. 18, 145.

SvedmYR, N. (1966) Studies on the relationships between some metabolic effects of thyroid hormones and catecholamines in animals and man. Acta physiol. scand. 68, Suppl. 274, 1.

TAPLEY, D.F. (1964) Mode and site of action of thyroxine. Proc. Mayo Clin. 39, 626.

TATA, J.R. (1964) In: Actions of Hormones on Molecular Processes (Ed. by G. Litwack and D. Kpitchevsky), p. 58. Wiley, New York.

TATA, J.R. (1967) Ribosomes and thyroid hormones. In Colloq. der Gesellschaft für physiol. Chemie, Berlin, p. 87. Springer Vg, Mosbach/Baden.

Tata, J.R., Ernster, L., Lindberg, O. Arrhenius, E., Pedersen, S. \& Hedman, R. (1963) The action of thyroid hormones at the cell level. Biochem. J. 86, 408.

Turner, P., Granville-Grossman, K.L. \& Smart, J.V. (1965) Effect of adrenergic receptor blockade on the tachycardia of thyrotoxicosis and anxiety state. Lancet, ii, 1316.

URBANSKI, F.X. (1967) Medullary thyroid carcinoma, parathyroid adenoma, and bilateral pheochromocytoma. An unusual triad of endocrine tumours. J. chron. Dis. 20, 627.

WALDSTEn, S.S. (1966) Thyroid-catecholamine interrelationships. Ann. Rev. Med. 17, 123.
WAYNE, E.J. (1960) Clinical and metabolic studies in thyroid disease. Brit. med. J. i, 1 and 78.

WILliams, E.D. (1965) A review of 17 cases of carcinoma of the thyroid and phaeochromocytoma, J. clin. Path. 18, 288.

Williams, E.D. (1967) Medullary carcinoma of the thyroid. Symposium on the thyroid gland. Suppl. J. clin. Path. 20, 395.

Williams, E.D. \& Pollock, D.J. (1966) Multiple mucosal neuromata with endocrine tumours: a syndrome allied to Von Recklinghausen's disease. J. path. Bact. 91, 71.

Williamson, J.R. (1966) Metabolic effects of epinephrine in the perfused rat heart. Molec. Pharmacol. 2, 206.

Wilson, W.R., Theilen, E.O., Hege, J.H. \& Valenca, M. (1966) Effects of beta adrenergic receptor blockade in normal subjects, before, during and after triiodothyronineinduced hyper-metabolism. J. clin. Invest. 45, 1159.

Wiswell, J.G., Hurwitz, G.E., Coronho, V., Bing, O.H.L. \& CHILD, D.L. (1963) Urinary catecholamines and their metabolities in hyperthyroidism and hypothyroidism. $J$. clin. Endocr. 23, 1102.

WolfF, E.C. \& WoLFF, J. (1964) The mechanism of action of the thyroid hormones. The Thyroid Gland (Ed. by R. Pitt Rivers and W.R. Trotter), Vol. 1, Chap. II, pp. 237-282. Butterworths, London.

WoOlner, L.B., Beahrs, O.H., BlaCk, B.M., McConahey, W.M. \& KEATING, F.R., JR (1961) Classification and prognosis of thyroid carcinoma. A study of 885 cases observed in a thirty year period. Amer. J. Surg. 102, 354. 